\title{
Social Exclusion among Women Living in Rural Areas Suffering from Hypertension: The Case of Dikgale-Communities
}

\author{
M. L. Shirindi ${ }^{1}$, J. C. Makhubele ${ }^{1}$, V. Mabvurira ${ }^{1}$, and J. Fraeyman ${ }^{2}$ \\ ${ }^{1}$ Social Work Department, School of Social Science, University of Limpopo, \\ Private Bag X 1106, SOVENGA, 0722, South Africa \\ ${ }^{2}$ Research Group Medical Sociology and Health Policy, University of Antwerp, Belgium \\ ${ }^{1}$ Telephone: +27 (0)12 429 6060, \\ ${ }^{1}$ Facsimile: +27 (0) 152683636 , \\ E-mail: ${ }^{1}$ linda.shirindi@gmail.com and ${ }^{2}$ Jabulani.Makhubele@ul.ac.za
}

KEYWORDS Social Exclusion. Hypertension. Women. Rural Area. Poverty

\begin{abstract}
Social exclusion is the consequence of long-lasting forms of instability that undermines the capacity of rural women. The objective of the study was to explore the effect of social exclusion among women suffering from hypertension. The researchers used a qualitative exploratory research design. A purposive sampling technique was used to select sixty (60) Black African women suffering from hypertension. Five (5) focus group interviews and ten (10) in-depth interviews were conducted with women living with hypertension. The NVivo programme was used to manage and organize qualitative data. The findings indicated that deep structural factors such as poverty, unemployment and inequality describe how women experience social exclusion and how these factors can exacerbate the heath conditions of women living with hypertension. In order to deal with the challenge of poverty, unemployment and inequality, more intervention programmes to increase empowerment should be implemented.
\end{abstract}

\section{INTRODUCTION}

The concept of social exclusion is seen as covering a remarkably wide range of social, economic and health problems among women (Sen 2000 , 2007). The practical context of identifying the "excluded" Lenoir in Sen (2000:1) indicated the following as constituting the "excluded": Single parents, multi-problem households and other social 'misfits', amongst others. Social exclusion creates a sense of powerlessness, hopelessness and depression that further diminish the possibilities of inclusion in society. The presence of social exclusion and its impact upon health is dramatically a concern in today's era among women living in rural area suffering from hypertension. In this research paper, poverty is related with a lack of material resources that restricts participation, and the resulting exclusion refers to:

[...] the dynamic process of being shut out, fully or partially, from any of the social, economic, political and cultural systems which determine the social integration of a person in society (Walker and Walker 1997:8).

Being excluded from the mainstream life of society and treated as less than equal leads to poorer health and greater risk of untimely death (WHO 2003). For rural women, the stresses of being unemployed, living in poverty and the experiences of gender inequalities are particularly harmful. Individuals living below the poverty level are more likely to have hypertension compared with those living at the highest level of income (CDC 2013; US Department of Health and Human Services 2013; Palmer et al. 2006). One of the characterizations of poverty in the lives of women living in rural area is simply a shortage of income. The impoverishment of their lives results frequently from the inadequacy of income, and in this sense low income must be an important cause of poor living. The idea of seeing poverty in terms of poor living is not emphatically 'new' (Sen 2000). In the Aristotelian perspective, an impoverished life is one without the freedom to undertake important activities that a person has reason to choose (Sen 2000).

In South Africa, around half of the population, that is, 22 million live in poverty (Poverties 2013). UN Secretary General Kofi Annan, in his 2001 address to the World Health Assembly, noted: "The biggest enemy of health in the developing world is poverty" (World Bank 2002:12). Chronic diseases such as hypertension were thought to be diseases of the affluent, but poor populations are now equally affected. This is largely due to the environment in which the poor reside, and socio-economic circumstances that 
influence their diets and physical activity patterns (Mvo et al. 1999). The open secret about poverty in South Africa is that it has a woman's face (Hunter-Gault 2006). Hypertension is a common condition among rural women in South Africa and is a risk factor for heart attacks, stroke, left ventricular hypertrophy, renal disease, and blindness (Steyn et al. 2006). A complex constellation of social, economic, and behavioural factors is behind the rise in hypertension. Internationally, there is a well-established correlation between low socio-economic circumstances, poor health and well-being and an increased risk of mortality among women with serious health conditions (Lynch et al. 1997; Ho et al. 2008).

Unemployment can be a major causal factor predisposing women to social exclusion (Sen 2000; WHO 2003; Valtonen 2008). Unemployment puts health at risk and the health effects of unemployment are linked to both its psychological consequences and the financial problems it brings. Taking a broader view of poverty, the nature of the deprivation of the unemployed includes the loss of freedom as a result of joblessness. According to Tompa et al. (2009), unemployment is related to poor health through various pathways. Firstly, unemployment often leads to material deprivation and poverty by reducing income and removing benefits that were previously provided by one's employer. Secondly, losing a job is a stressful event that lowers one's self-esteem, disrupts daily routines, and increases the chances of having hypertension. Thirdly, unemployment increases the likelihood of turning to unhealthy behaviours such unhealthy lifestyle.

Women experience social exclusion more than men (Mashiri and Mahapa 2002; Mokomane 2012). The main reason for this is that women carry more responsibilities for raising children and taking care of housework. Radical feminism indicates that most African cultures require women to be subservient, and play a traditional role as caregivers in families (McDowell and Pringle 1992; World Bank 2012). The family is held together by women, and they are regarded as 'natural carers' (Rabbort and Wallace 1990:51) Thus, the physical burden imposed by hypertension on women is heavy as they are no longer able to fulfill their multiple roles. The other major concern in terms of gender inequality is the lack of affordable and high quality day-care. This forces women to stay at home more and take care of family responsibilities.
Social service practitioners can help address the challenges brought by social exclusion on women, particularly to those suffering from hypertension. Theories in social sciences such as the ecological perspective have emphasized the importance of developing a proper fit between the individual and his or her environment. As such, interventions involving social networks and support of women living with hypertension are fundamental to the theory and practice (Schnall 2005). Social service professionals should be aware that women in rural areas, because of material deprivation and psycho-social stress, are susceptible to health problems such as hypertension. Through health promotion and services, support and advocacy, social services' practitioners can provide a bridge to bring women back to a status of stability and control. By helping these women to identify their own strengths and support, they can improve and enhance their social functioning and well-being (Shepperd 2006).

\section{Theoretical Framework}

In this study, feminism theory was used to analyse the concept of social exclusion in the context of poverty, unemployment and inequality. Social exclusion has been the argument of feminist theories specifically looking at the experiences of women (Diquinzio 1993; Goldenberg 2007). In essence social exclusion captures elements of inequality and disadvantages factors that have long been a challenge for social sciences practice.

Feminism has shown, and continues to show, that poverty is very much a feminist issue (Malik et al. 2012). Women living with hypertension find it to be a struggle to reach out of poverty because of the inequality existing in issues of employment, illiterate and being the backbone of taking care of their families. They remain powerless, while trapped in poverty.

Feminists also attribute the 'feminization of poverty' to women's vulnerability brought about by the patriarchal, and gender biased issues (Cliffs Notes 2013) which affect the health and well-being of many women living in rural areas. The term "feminization of poverty" was introduced by Diana Pearce (1978) in the research paper: "The feminization of poverty. Women: Work and Welfare” (Broza-Grabowska 2011). Feminization of poverty describes a phenome- 
non in which women represent disproportionate percentages of the world's poor (Vardhan 2014; Chant 2006). This concept is not only a consequence of lack of income, but is also the outcome of the deprivation of capabilities and gender bias present in both societies and governments (Chant 2006). Another consequence includes the poverty of choices and opportunities, such as the ability to lead a long, healthy life, and enjoy the benefit of basic rights such as freedom, respect, and dignity. The concept of social exclusion is seen in the feminization of poverty.

\section{Aim and Objectives}

The aim of this study was to explore the effect of social exclusion among women living in rural areas suffering from hypertension.

The specific objective of this study was:

- To explore the effects of social exclusion among women suffering from hypertension.

\section{METHODOLOGY}

A qualitative exploratory research design was used to better understand how social exclusion contributes to difficult life of rural women, particularly those who are suffering from hypertension. Focus group data collection technique was used to explore the influence of social exclusion among women living in rural areas suffering from hypertension. Ethical clearance was obtained from Turfloop Research and Ethics Committee (TREC) of the University of Limpopo to conduct the study.

A purposive sampling approach was used to identify and recruit eligible participants $(\mathrm{N}=50)$ for the five (5) focus groups conducted, and indepth interviews $(\mathrm{N}=10)$ were conducted. Each focus group discussion had an assistant moderator, who took notes throughout the discussions, listening to notable quotes, noting several key points in response to each question, monitoring recording equipment, drawing a diagram of the seating arrangements, giving an oral summary and feedback after each discussion. The focus groups and interviews were guided by a semi-structured questionnaire consisting of open-ended questions and discussed the following themes: description of poverty, unemployment and gender inequality.

The participants were recruited from Dikgale Health and Demographic Health Suivellance Survey (HDSS). The Dikgale DSS site is located in the Central Region, Capricorn District of Limpopo Province, South Africa. It is approximately $40 \mathrm{~km}$ from Polokwane, the capital city of Limpopo Province and $15 \mathrm{~km}$ away from the University of Limpopo, located about 30 kilometres east of the provincial capital city (Alberts and Burger 2002). The participants had to meet several criteria to be considered for the study. Firstly, only black women were selected. Secondly, only group members who were between 30 and 100 years were considered for the study. Lastly, they had to be diagnosed with hypertension. All the 60 women suffering from Hypertension were black African and resided in Dikgale and surrounding villages within the Capricorn district, Limpopo Province. According to Statistics South Africa (2005), the Black African population accounts for the majority of citizens in South Africa. The majority of the people in Limpopo Province are mostly Black African.

The NVivo programme was used to manage and organize qualitative data. The results were presented in a thematic analysis. The analysis emphasizes pinpointing, examining, and recording patterns (or "themes") within data.

\section{RESULTS}

Presentation of the results and subsequent discussions are based on three themes: poverty, unemployment and gender inequality. We illustrate the results with quotations from the participating women, stating the name of the residence and whether they participated in an interview or focus group discussion (FGD).

\section{Poverty}

All the women who participated in the study lived in poverty. The participants quoted poverty as the most important factor in social exclusion. They explained what poverty meant to them, and their reactions showed a complex understanding of poverty that went beyond financial instability. The participants described poverty as a human rights issue and as a cause of social exclusion. One participant said:

"We live in hunger and even unable to afford to buy healthy food. Not having enough food to eat worsens my condition of hypertension. The worst thing, I am not concerned with me alone, what about my family? As a single parent it gets tougher and tougher."

The effect of poverty on their health was also discussed. Poverty was experienced as hav- 
ing a negative effect on mental and physical health. Stress, depression, exhaustion, low selfesteem and poor nutrition were repeatedly termed the consequences of poverty.

"I am bothered by my living condition. As a result I become depressed, and we were taught at the clinic not to think too much, because our hypertension condition will not improve."

Their experiences of poverty created a sense of disrespect from other members of their community to feelings of low self-esteem, lack of self-confidence and hopelessness. One participant said that her status of poverty had an impact on her identity and how she is perceived by her environment:

"It hurts to know that we are judged by what we have, but not who we are....This creates a feeling of not trusting myself....I sometimes feel hopeless."

The participants also described poverty as a socially isolating condition that resulted in feeling stuck, miserable and depressed. Being unable to afford to participate in social activities (community and family based events) was a reality for the majority of the participants. They identified the difficulties of remaining resilient in the face of hostility, judgement, pity and shame.

"It is difficult to face each day with confidence, as I think that to some community members, I am a disgrace because of my situation. Sometimes I become angry at myself, asking the question, what did I do to experience this situation?"

"My family has become a burden to our neighbours, seeing that when we lack for instance, salt, cooking oil or mealie meal we run to them."

Poverty makes it difficult for women to engage in social activities as a mother or woman; this creates a feeling of failure. The following excerpts illustrate some of the participants' views:

"You feel not being a complete mother or woman, because the social activities done by other women. I fail to do them because of lack of money."

\section{Unemployment}

Unemployment was another issue that emerged during the participants' discussion of social exclusion. Employment was identified as a way out of poverty. They expressed frustra- tion as a result of lack of opportunities or support in finding well-paid employment. Possibilities to improve their financial situation seemed limited. The participants' further indicated that unemployment worsened their hypertension condition. The financial instability was recognized as both compromising the women's quality of life and trapping them in a deepening cycle of debt and financial obligations. The majority of the participants pointed out that unemployment affected their health, especially when worrying about what to eat, and how to meet the basic needs of the family. They expressed frustration, fear, guilt and sadness about the ways in which unemployment affected them, for never having enough money to pay their bills/debts. The following excerpts illustrate some of the participants' views:

"The standard of living is costly, especially for those of us who are jobless and suffering physically. The social grant I receive for three children is not enough to meet the basic needs of the family. I must buy food, electricity (energy) and ensure that burial societies are paid...I also have too many debts and I am unable to repay them."

The participants' monthly household income was received from social grants and self-employment. Thirty-four participants were pensioners, and their means of survival was old age grant of ZAR1260-00 per month. Six of the participants were domestic workers (also benefit from a social grant), earning approximately ZAR700-00 per month, and eight were unemployed and their families live on the child support grants of their children. Each child receives ZAR230.00. Nine women were self-employed, and made a profit of between ZAR800.00 and ZARR1000.00 every month. Only three of the respondents were students. Two participants gave the following responses when they were asked about their source of income or means of survival:

"I am a chronic disease patient who depends on a social grant. Due to shortage of medication in the clinics and hospitals, I am forced to use the grant to buy medication, as a result my family needs are not adequately met."

It is clear that low income can have a considerable impact on medication adherence and consequently health status. In corroboration of the above, another participant said:

"At times when I do not have money to buy medication, it becomes a problem as I will de- 
fault and not adhere to the medication treatment. It is tough."

The participants indicated that they found it difficult to get jobs due to lack of work experience, illiteracy and lack of relevant training.

"I stopped going to school while doing grade 11. You know what was the reason? I had to go and look for a job, although it was not easy to get employed, since I did not have any work experience."

"As a granny like this, I do not know the gate or entrance of a school. I grew up knowing that a woman does not go to school, but has to take care of the cooking and other family responsibilities."

\section{Gender Inequality}

Gender inequality is particularly a dominant form of social exclusion. The participants indicated that the community views women as having a lower status, a stance which is reinforced by cultural norms, beliefs and expectations. A participant said:

"Culturally, I am expected to bear children and perform household work; if I fail to bear children, I must allow my husband to marry a second wife. If I do not allow him, his parents will encourage him to take a second wife. This, as a result, creates health problems."

For the most part, women are the backbone of their families, and as they conduct their dayto-day activities, these may limit them access to education and employment opportunities. One participant said:

"In addition to what she said, not much of a choice is given to us to seek employment, since we must take care of the children".

In corroboration of what has been said previously, another participant said:

"We lack day-care centres where we can take our children, so that we can go and look for jobs'. I think if the government can make child care centres available for us, we can manage to stand up and do something for our families. The hypertension medication we drink requires us to have eaten first, and when food is not available then that's a problem. If you can check among us, we did not go to school and reach higher grades/standards, because as a mother "Ke swara thipa ke bogaleng" (a mother holds the knife by its cutting edge).
The tenor of the preceding proverb reveals that it is a mother who will go out of her way, even taking risks at times, for the safety and welfare of her children.

\section{DISCUSSION}

The participants provided varied but vivid explanations reflecting their understanding and experiences of social exclusion and how it causes poverty, unemployment, and gender inequality, and how these factors worsen their hypertension condition. Women living with hypertension were selected to participate in this study given that hypertension is the most common chronic condition in South Africa (Malaza et al. 2912; Sliwa et al. 2014).

Several reasons may explain why women living in rural areas are socially excluded and vulnerable to hypertension. The study revealed that, for many women, a diagnosis of hypertension carries a profound physical, psychological and social burden when living in a poverty stricken family and at the same time being unemployed. Managing and living with the diagnosis is complex and stressful. Social exclusion is one way of conceptualizing disadvantage, traditionally seen in terms of "poverty", "hardship", and "destitution", all of which focus on material deprivation and the consequent personal distress of want and misery (Boardman 2011). There are, however, many competing views about the ways in which exclusion can arise (Levitas 1998). One view stresses the way in which poverty limits social participation of women suffering from hypertension and acts as a major cause of exclusion, compounded by other types of inequality. Similarly, it can be stated that social exclusion refers to various forms of economic, social and psychological deprivation among women who lack adequate ownership of, control of, or access to resources for achieving a minimum level of living. It is a multi-dimensional problem involving income, consumption, nutrition, health, education, housing, crisis coping capacity, access to credit and other aspects of living (Wazed 2012).

According to the participants, poverty was expressed as the inability to meet certain basic needs and to turn their situations around. Their statements expressed despair, fear and a lack of choice. Poverty was also understood as a human rights issue, and many participants felt that 
being unable to meet their basic needs was an issue of social inequality. Not so surprising, poverty was also defined as a phenomenon that causes the poor person to experience disrespect, stigma and discrimination. Today, in South Africa, Limpopo province, women are suffering from rather high levels of poverty and food insecurity. According to the Living Conditions Survey (LCS) 2008/2009 results, using the food poverty line, Limpopo is the poorest province (48.5\%) (Statistics South Africa 2012). The survey results also showed the total number of females in the country estimated to be greater than that of males, and females had a higher poverty headcount (27.3\%) than males. According to Vorster (2010), poverty cannot be defined only in economic terms, but also as a serious deprivation of the capability to lead a minimally acceptable life. It was shown in the study that poverty is characterized by a lack of job opportunities, low personal income and other physical and environmental factors, such as the unavailability and costs of medical care and other facilities. Several studies (Ataguba et al. 2011; Harris et al. 2011) have revealed that people with the lowest socio-economic levels have higher health and illness rates.

South Africa was found to be one of the countries having the highest unemployment rate in the world, currently standing at 25.2 percent (that is, by the narrow definition of unemployment) based on figures released by STATSSA (2008) (Kyei and Gyekye 2011). Unemployment in Limpopo Province is predicted strongly and positively among women (Kwabena and Gyekye 2011). Employment provides income, a sense of identity and helps to structure day-to-day life. In this study, unemployment was found to be the leading cause of material and social deprivation, psychological stress, and the adoption of health-threatening coping behaviours. This resonates with a previous study by Tompa et al. (2008). The Dikgale area is one of the poorest villages in South Africa (Alberts et al. 1999; Mashinya et al. 2014). Community members are mostly pensioners, while others work as farm labourers (seasonal work) on neighbouring farms, or as domestic workers in nearby towns. The unemployment rate in the area is also rather high. The participants $(\mathrm{N}=36)$ survive on social grants received from the government because of the low income they receive and consequently tend to be in poorer health than the well-to- do. For instance, the participants do not usually live near hospitals and primary care doctors. In addition, because of their social and economic status they would not be in a position to afford expensive treatment.

In rural areas, gender inequalities exist because of a range of interlinked social, economic and political factors (Albertyn 2009). There are still traditions, customs and social norms that govern the intricate workings of rural societies, which act as a constraint on women's activities and restrict their ability to participate in good paid employment and to attain economic independence. The commonly held view is that, it is a woman's responsibility to work in the home: cooking, cleaning, and looking after the children, the sick, and the elderly. These practices are extremely difficult to eradicate and are detrimental to women's capacity to develop as productive members of society; they stifle women's economic empowerment and exacerbate the risk of health problems.

\section{CONCLUSION}

It is evident from the participants' individual experiences that social exclusion is complex and has a wide-ranging impact on their lives. From the participants' perspective, social exclusion relates not simply to a lack of material resources, but also to matters such as inadequate social participation, inadequate access to education and general services and a lack of power.

\section{RECOMMENDATIONS}

Social service practitioners including social workers, amongst others, should know and understand the challenges posed by poverty, unemployment and inequality and that these three are at the core of social exclusion. Social service practitioners can play an active role, as they are often in direct contact with those at risk for, or suffering from hypertension. Social service practitioners should analyse social exclusion from a multidimensional perspective, and to understand that there are many issues of gender inequality that cannot be resolved by one solution. Instead of focusing only on lack of income, it is crucial to analyse human poverty and the deprivation of capabilities as a way to focus on deeprooted structural causes of social exclusion that policy makers may then use to empower women. 


\section{REFERENCES}

Alberts M, Burger S, Tollman SMT 1999. The Dikgale Field Site. South African Medical Journal, 89(8): 851-852.

Alberts M, Burger, S 2002. Dikgale DSS, South Africa. In: Population and Health in Developing Countries, Vol 1, Population, Health, and Survival in INDEPTH Sites (Vol. 1, pp. 207-211). Canada: International Development Research Centre. From <http://www. cdc.gov/features/africanamericanhistory > (Retrieved on 12 February 2014).

Albertyn C 2009. 'The Stubborn Persistence of Patriarchy?' Gender Equality and Cultural Diversity in South Africa. Constitutional Court Review. Pretoria: Government Printer, pp. 166-207.

Ataguba JE, Akazili J, McIntyre D 2011. Socio-economic-related health inequality in South Africa: Evidence from General Household Surveys. International Journal for Equity in Health, 10: 48.

Boardman J 2011. Social exclusion and mental health - how people with mental health problems are disadvantaged: An overview. Mental Health and Social Inclusion, 15(3): 112 - 121.

Broza-Grabowska P 2011. Women's experience of poverty in context of power inequality and financial abuse in intimate relationship- Social work and society. International Online Journal (SW and S), 9(2): 1-6.

Centers for Disease Control and Prevention -CDC 2013. High Blood Pressure. From <www.cdc.gov/features/ africanamericanhistory $>$ (Retrieved on 14 February 2014).

Chant S 2006. Re-thinking the 'Feminization of Poverty' in relation to aggregate gender indices. Journal of Human Development, 7(2): 201-220.

Cliffs Notes 2013. Causes and Effects of Poverty. Houghton Mifflin Harcourt. From <http://www. cliffsnotes.com/sciences/sociology/social-and-globalstratification/Causes-and-effects-of-poverty> (Retrieved on12 May 2014).

Diquinzio P 1993. Exclusion and Essentialism in Feminist theory: The problem of mothering. Hypatia, 8(3): $1-20$.

Goldenberg MJ 2007. The problem of exclusion in feminist theory and politics: A metaphysical investigation into constructing a category of woman. Journal of Gender Studies, 16(2): 139 - 153.

Harris B, Goudge J, Ataguba JE McIntyre D, Nxumalo N, Jikwana S, Chersich M 2011. Inequities in access to health care in South Africa. Journal of Public Health Policy, 32: S102-S123.

Ho K, Dobb G, Knuiman M, Finn J, Webb S 2008. The effects of the socio-economic status on outcomes for seriously ill patients: A linked data cohort study. The Medical Journal of Australia, 189: 29-30.

Hunter-Gault C 2006. African Women and the Struggle Against Poverty. From <http://www.npr.org/templates/story/story.php?storyId=5627508 $>$ (Retrieved on 14 February 2014).

Kyei KI, Gyekye KB 2011. Determinants of unemployment in Limpopo Province in South Africa: Exploratory studies. Journal of Emerging Trends in
Economics and Management Sciences (JETEMS), 2(1): 54-61.

Lenoir R 1974. Les Exclus: Un Francais sur Dix. In: A Sen (2000) (Ed.): Social Exclusion: Concept, Application, and Scrutiny. Volume 1. Social Development Papers. Paris: Asian Development Bank: Office of Environment and Social Development.

Levitas R 1998. The Inclusive Society? Social Exclusion and New Labour. Basingstoke: Macmillan.

Lynch J, Kaplan G, Shema S 1997. Cumulative impact of sustained economic hardship of physical, cognitive, psychological and social functioning. The New England Journal of Medicine, 337(1): 1889-1895.

Malaza A, Mossong J, Bärnighausen T, Newell ML 2012. Hypertension and obesity in adults living in a high HIV prevalence rural area in South Africa. PLoS One, 7(10): e47761.

Malik FM, Muhammad SE, Hamaad N, Zain-ul A, Hamid S 2012. Feminism: The Perspectives Arguments. From < www.slideshare.net/moonzajer/feminism> $($ Retrieved on 11 May 2014).

Mashiri M, Mahapa S 2002. Social Exclusion and Rural Transport: A Road Improvement Project. Tshitwe, Northern Province, South Africa: Zed Books.

McDowell L, Pringle R 1992. Defining Women: Social Institutions and Gender Divisions. Oxford: Polity Press.

Mokomane Z 2012. Types of Good Practices Focusing on Family Poverty Reduction and Social Exclusion. South Africa: Human Sciences Research Council of South Africa.

Mvo Z, Dick J, Steyn K 1999. Perceptions of overweight African women about acceptable body size of women and children. Curationis (Nursing), 22(2): 27-31.

Palmer G, MacInnes T, Kenway P 2006. Monitoring Poverty and Social Exclusion in Scotland 2006. Joseph Rowntree Foundation and the New Policy Institute, New York. From <http://www.jrf.org.uk/ knowledge/findings/socialpolicy/1980.asp> (Retrieved on 19 February 2014).

Pearce D 1978. The feminization of poverty: Women, work, and welfare. Urban and Social Change Review, 11: 28-36.

Poverties 2013. Poverty in South Africa, Taming Globalization and Inequalities. Research for Social and Economic Development. From <http://www. poverties. org/poverty-in-south-africa.html> (Retrieved on 11 February 2014).

Rabbort P, Wallace C 1990. An Introduction to Sociology: Feminist Perspectives. New York: Brooks/Cole Publishing.

Schnall E 2005. Social support: A role for social work in the treatment and prevention of hypertension. Einstein J Biol Med, 21: 50-56.

Sen A 2000. Social Exclusion: Concept, Application, and Scrutiny. Social Development Papers 1. Manila, Philippines: Asian Development Bank.

Sen A 2007. Amartya K Sen and social exclusion. Ann Nevile, Development in Practice, 17(2): 249-255.

Sheppard M 2006. Social Work and Social Exclusion: The Idea of Practice. Hampshire: Ashgate Publishing. 
Sliwa K, Ojji, D Bachelier K 2014. Hypertension and hypertensive heart disease in African women. Clinical Research in Cardiology, 103(7): 515-523.

Statistics South Africa. 2005. Midyear Population Estimates, South Africa. From<www.statssa.gov.za> (Retrieved on 11 March 2006).

Statistics South Africa, 2012. Poverty Profile of South Africa- Living Conditions Survey 2008-2009- Application of the Poverty Lines on the LCS 2008/ 2009. Pretoria: South Africa.

Steyn K, Fourie J, Temple N (Eds.) 2006. Chronic Diseases of Lifestyle in South Africa: 1995 - 2005. Technical Report. Cape Town: South African Medical Research Council.

Swartz K 2009. Health care for the poor: For whom, what care, and whose responsibility? Focus, 26(2): 69-74.

Tompa E, Polanyi M, Foley J 2008. Labour market flexibility or employment insecurity? Towards healthy and productive work. Chapter 6. In: D Raphael (Ed.): Social Determinants of Health: $\mathrm{Ca}-$ nadian Perspectives. $2^{\text {nd }}$ Edition. Toronto: University of Toronto Press, pp. 88-98.

US Department of Health and Human Services 2013. Poverty Guidelines, Research, and Measurement. From <http://aspe.hhs.gov/poverty/index.cfm> (Retrieved on 15 December 2013).
Valtonen K 2008. Social Work and Migration: Immigrant and Refugee Settlement and Integration. Farnham: Ashgate Publishing.

Vardhan R 2014. An analysis of impact of inflation on female headed household. EPRA International Journal of Economic and Business Review, 2(5): 1-5.

Vorster HH 2010. The link between poverty and malnutrition: A South African perspective. Health SA Gesondheid, 15(1): Art \#435, 6 pages.

Walker A, Walker C 1997. Britain divided: The growth of social exclusion in the 1980s and 1990s. Klalker, A. and Walker C. (Eds.): Child Poverty Action Group. London: CPAG,

Wazed Soniya 2012 Gender and Social Exclusion/Inclusion: A Study of Indigenous Women in Bangladesh. Thesis, Unpublished. Institute of Applied Social Sciences, College of Social Sciences. Britain: University of Birmingham.

World Bank 2012. World Development Report: Gender Equality and Education. Washington D C : World Bank, P. 84.

World Bank 2002. World Development Report. From $<$ www.unesco.org> (Retrieved on 13 May 2014).

WHO 2003. Social Determinants of Health: The Solid Fact. International Center for Health and Society. From <http://www.euro.who.int/_data/assets/pdf> (Retrieved on 13 May 2014). 